\title{
Enhancing contraceptive usage by immediate postpartum intra uterine contraceptive device insertion with evaluation of safety, acceptability and expulsion
}

\author{
Lekhya Tirupati, Pradeep Shivaraju*, Krishna Lingegowda, Sabitha Srinivasan
}

Department of Obstetrics and Gynecology, PES Medical College, Kuppam, Andhra Pradesh, India

Received: 03 August 2018

Accepted: 01 September 2018

*Correspondence:

Dr. Pradeep Shivaraju,

E-mail: drpradi@gmail.com

Copyright: () the author(s), publisher and licensee Medip Academy. This is an open-access article distributed under the terms of the Creative Commons Attribution Non-Commercial License, which permits unrestricted non-commercial use, distribution, and reproduction in any medium, provided the original work is properly cited.

\begin{abstract}
Background: India's population which crossed one billion in 2000 is projected to reach 1.53 billion by 2050 making India the most populous country in world. In India $65 \%$ of women have unmet need for family planning in the first post-partum year. PPIUCD is highly effective, safe, long-acting, coitus independent and rapidly reversible method of contraception with very few side effects. Since there is tenfold increase in institutional deliveries due to maternity benefit schemes, postpartum period is potentially an ideal time to begin contraception as women are more strongly motivated and these women would leave the hospital with contraceptive in place.

Methods: The present study was a prospective study to assess the acceptance rate of PPIUCD insertion and evaluation of safety of $\mathrm{Cu}$ T 380A when inserted within ten minutes of placental expulsion in 100 women delivering at PESIMSR, Kuppam. A specially designed proforma was used to collect the data of women attending hospital between period June 2016 to June 2017.

Results: Out of 486 patients who were counselled only 100 women (20.57\%) accepted for PPIUCD insertion. The acceptance rate of PPIUCD is $20.57 \%$. Of 100 women who had PPIUCD insertion, 91 were seen at follow up, 76 (78.12\%) women were continuing with no complaints and only 15 (16.4\%) women developed complications. PPIUCD was found to be safe as there was no reported case of perforation or failure during usage. The complications like expulsion was found to be $1.09 \%$, infection $5.4 \%$, pain abdomen $5.4 \%$, bleeding $1.09 \%$ and missing strings $5.4 \%$. Conclusions: PPIUCD was demonstrably safe, having no reported case of uterine perforation. Expulsion rates are low implying more retention rates, thus more effective. Public awareness regarding the concept and advantages of PPIUCD insertion can be improved by mass media approach and creating strategies and training programmes under Government policies.
\end{abstract}

Keywords: Postpartum intrauterine contraceptive device, Post placental IUCD

\section{INTRODUCTION}

Postpartum period is one of the critical times when both woman and newborn need a special and integrated package of health services as morbidity and mortality rates are quite high during this period and also the women are vulnerable to unintended pregnancy. WHO showed that pregnancies taking place within 24 months of a previous birth have a higher risk of adverse outcomes like abortions, premature labor, postpartum hemorrhage, low birth weight babies, fetal loss and maternal death. ${ }^{1}$

Approximately $27 \%$ of births in India occur in less than 24 months after a previous birth. ${ }^{2}$ Another $34 \%$ of births 
occur between 24 and 35 months. $61 \%$ of births in India occur at intervals that are shorter than the recommended birth-to-birth interval of approximately 36 months. ${ }^{2}$

Women are highly motivated and receptive to accept Family Planning (FP) methods during the postpartum period. Family planning can avert nearly one-third of maternal deaths and $10 \%$ of child mortality when couples space their pregnancies more than two years apart. ${ }^{1}$

Demographicand Health Survey show that 40 percent of women in the first year postpartum intend to use a family planning (FP) method but are not doing so.

Introduction of JSY and JSSK has increased institutional deliveries. Labor room is attended by large numbers of beneficiaries every day, delivery provides a convenient opportunity for the woman to receive IUCD services. This is particularly important for woman who has limited access to medical care.

Institutional deliveries have increased significantly all across the country, thereby creating opportunities for providing quality postpartum family planning services. The postpartum services need to be strengthened by integrating maternal and child health and Family planning services at each level of health facility from the district hospital to the sub-centre.

This study was conducted to evaluate the safety and acceptance rate of immediate postpartum intrauterine contraceptive device (PPIUCD) insertion in women delivering vaginally or by cesarean section.

The aim and objectives of the study was to determine percentage of women accepting immediate PPIUCD insertion, to describe the factors associated with acceptability of immediate PPIUCD insertion in women according to their socio-demographic variables, age, parity, future pregnancy desire, and also reasons for unacceptance. This study also determines the rate of uterine perforation, expulsion, pelvic infection, missing threads and displacement following PPIUCD insertion among acceptors.

\section{METHODS}

This study was a prospective, interventional and analytical study conducted in Department of Obstetrics and Gynecology, PES Institute of Medical Sciences and Research, Kuppam, Andhra Pradesh from June 2016 to May 2017. The hospital is University teaching hospital in Kuppam and is a tertiary referral center for the primary and secondary level health care centres.

Sample size is 100. Women delivering in PES institute of medical sciences and research either vaginally or by caesarean section, fulfilling inclusion criteria will be included in the study after obtaining informed consent.

\section{Inclusion criteria}

- Women delivering vaginally or by caesarean delivery at our institute.

- Counselled for IUD insertion in prenatal period or in early labour.

- Willing to participate in the study.

- Age 18 years or older.

- Willing and able to sign an informed consent.

- Willing to have their address recorded and to come for follow up at 6 weeks.

\section{Exclusion criteria}

- Haemoglobin less than $8 \mathrm{~g} / \mathrm{dl}$

- Rupture of membranes for more than 18 hours

- Chorioamnionitis

- Unresolved postpartum haemorrhage

- Obstructed labour

- Distorted uterine cavity by fibroid or congenital malformation of uterus

- Women allergic to copper.

Study included a structured questionnaire which include sociodemographic variables, obstetric parameters, reasons for acceptance and unacceptance of the patient, Consent for PPIUCD insertion, a check list and a PPIUCD follow up card.

Women in whom the PPIUCD was inserted were assessed before discharge and followed at two weeks and 6 weeks after IUCD insertion. Upon discharge a PPIUCD follow up card was given which contained information of the date of insertion and follow up visit, type of IUCD inserted, date of expiry of the IUCD and the telephone number of the principal investigator.

Pelvic examination was done, on per speculum examination if IUCD threads were long; they were cut 2 $\mathrm{cm}$ from external OS. If threads were not visible on per speculum examination, an ultrasound was performed to check for expulsions and confirm presence of intrauterine IUCD. If the women requested for removal of IUCD for any medical or personal reason, she was counselled, and intrauterine device was removed. Women were offered reinsertion of IUCD or alternative methods of contraception in case of expulsions/removals.

\section{Statistical analysis}

Data of individual case was entered in MS Excel sheet and was analyzed using statistical package of social sciences (SPSS) 21.0. Statistical significance was set at $\mathrm{p} \leq 0.05$.

\section{RESULTS}

The total number of deliveries during the study period was 3120. Among these deliveries 1529 women were 
eligible for PPIUCD insertion. A total of 486 women were approached. One hundred women (20.57\%) accepted PPIUCD insertion while almost four fifths of them declined insertion.

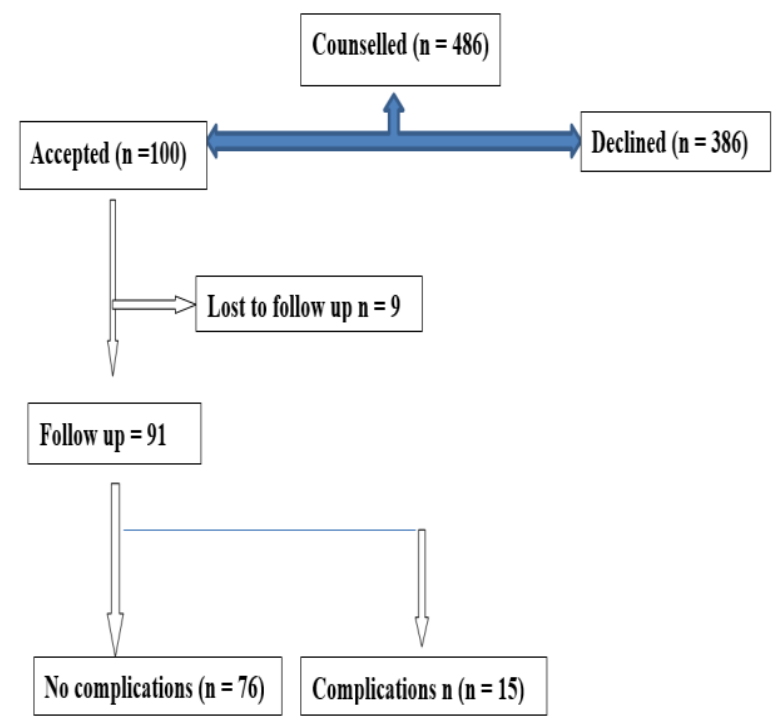

Figure 1: Recruitment of study participants.

Those women whom the PPIUCD was inserted were followed up at two weeks and six weeks. Nine women were lost to follow up, thus 91 were seen at two and six weeks after insertion of IUCD. Out of 91 women, 15 (16.48\%) developed complications. Table 1 represents the age distribution of women studied Majority were in age range of 20-25 (74\%).

Table 1: Age distribution.

\begin{tabular}{|lll|}
\hline Age & Number & $\%$ \\
\hline Below 19 & 6 & 6 \\
\hline $20-25$ & 74 & 74 \\
\hline $26-30$ & 20 & 20 \\
\hline Total & 100 & 100 \\
\hline
\end{tabular}

Their mean age was 22.8 years (2SD). Acceptance of the use of PPIUCD was higher among women with secondary education $(23.47 \%)$, than those with no formal education $(13.92 \%)$.

Table 2: Education distribution.

\begin{tabular}{|llll|}
\hline $\begin{array}{l}\text { Education } \\
\text { distribution }\end{array}$ & $\begin{array}{l}\text { Total } \\
\mathbf{n = 4 8 6}\end{array}$ & $\begin{array}{l}\text { Accepted } \\
\mathrm{n}=\mathbf{1 0 0}\end{array}$ & $\begin{array}{l}\text { Not accepted } \\
\mathrm{n}=386\end{array}$ \\
\hline $\begin{array}{l}\text { No formal } \\
\text { education }\end{array}$ & 136 & 22 & 114 \\
\hline $\begin{array}{l}\text { Primary } \\
\text { education }\end{array}$ & 189 & 34 & 155 \\
\hline $\begin{array}{l}\text { Secondary } \\
\text { education }\end{array}$ & 86 & 21 & 65 \\
\hline Higher education & 75 & 23 & 52 \\
\hline
\end{tabular}

This could be reasoned out that with increase in educational status of women there is increase in acceptance rate.

Table 3: Acceptance based on education.

\begin{tabular}{|l|l|l|}
\hline Education distribution & $\begin{array}{l}\text { Total } \\
n=486\end{array}$ & $\begin{array}{l}\text { Accepted } \\
n=100\end{array}$ \\
\hline No formal education & 136 & 22 \\
\hline & $86.08 \%$ & $13.92 \%$ \\
\hline Primary education & 189 & 34 \\
\hline Secondary education & $84.75 \%$ & $15.25 \%$ \\
\hline Higher education & 86 & 21 \\
\hline & $75.37 \%$ & $19.63 \%$ \\
\hline
\end{tabular}

$\mathrm{X}^{2}=7.83, \mathrm{P}=0.050 *$, significant, Chi-Square test

Among women who declined PPIUCD insertion, the majority of them not accepted because of misconceptions, fear of pain and bleeding.

Table 4: Reasons for unacceptance.

\begin{tabular}{|l|l|}
\hline Reasons for unacceptance & Number \\
\hline Misconception fear of pain and bleeding & 96 \\
\hline Need to discuss with partner & 78 \\
\hline Partners stay apart & 62 \\
\hline Prefer another method & 38 \\
\hline Partner/ family refusal & 34 \\
\hline Don't want immediately & 20 \\
\hline No reason & 54 \\
\hline Religious belief & 04 \\
\hline Fears cancer & 00 \\
\hline
\end{tabular}

The next most common reason for unacceptance is needing to discuss with partner and partners will stay apart. Maximum acceptors happen to be from Hindu community $(80 \%)$.

Table 5: Religion distribution.

\begin{tabular}{|lll|}
\hline Religion & Number & Age \\
\hline Hindu & 80 & 80 \\
\hline Muslim & 12 & 12 \\
\hline Christian & 8 & 8 \\
\hline Total & 100 & 100 \\
\hline
\end{tabular}

Majority of women in study were primiparous (90\%) and rest were multiparous $(10 \%)$.

Table 6: Parity distribution.

\begin{tabular}{|lll|}
\hline Parity & Number & Percentage \\
\hline 1 & 90 & 90 \\
\hline 2 & 7 & 7 \\
\hline 3 & 2 & 2 \\
\hline 4 & 1 & 1 \\
\hline Grand Total & 100 & 100 \\
\hline
\end{tabular}


Majority of women received counselling during early labour $(82 \%)$, antenatal period $(16 \%)$ and rest received counselling during poatpartum period $(2 \%)$.

Table 7: Time of counselling.

\begin{tabular}{|l|l|l|}
\hline Counselling & Number & $\%$ \\
\hline ANC & 16 & 16 \\
\hline Early labour & 82 & 82 \\
\hline Post-partum period & 2 & 2 \\
\hline Total & 100 & 100 \\
\hline
\end{tabular}

Among 100 women, 42 women (42\%) accepted for post placental (within 10 minutes) PPIUCD insertion and 58 women $(58 \%)$ accepted for intra caesarean insertion.

Table 8: Type of insertion.

\begin{tabular}{|lll|}
\hline Type of Insertion & Number & $\%$ \\
\hline Vaginal & 42 & 42 \\
\hline Intra caesarean & 58 & 58 \\
\hline Total & 100 & 100 \\
\hline
\end{tabular}

About 58 women (58\%) had come personally to hospital for follow up and 33 women (33\%) were followed up on telephone and 9 women do not come for follow up.

Table 9: Type of follow up.

\begin{tabular}{|lll|}
\hline Type of follow up & Number & $\%$ \\
\hline Clinic & 58 & 58 \\
\hline Telephonic & 33 & 33 \\
\hline Lost follow up & 09 & 09 \\
\hline Total & 100 & 100 \\
\hline
\end{tabular}

About 70 women $(70 \%)$ reviewed at 2 weeks and total of 83 women were followed up at 6 weeks.

Table 10: Time of follow up.

\begin{tabular}{|ll|}
\hline Follow up time & Number \\
\hline 2 weeks & 70 \\
\hline$>6$ weeks & 83 \\
\hline
\end{tabular}

15 women had complaints of abnormal bleeding, pain abdomen, fear of long strings, white discharge and expulsion. Majority of woman (83\%) who were followed up does not have any complaints.

Out of 100 women who were inserted PPIUCD, 91 women were followed up and the other 9 women were lost to follow up.

Out of these 91 women, 15 developed complications i.e., 5 women came with missing strings, 5 women with white discharge, 3 women have pain abdomen, 1 woman had excessive bleeding and 1 woman had expulsion of PPIUCD.
Table 11: Complications in PPIUCD users.

\begin{tabular}{|lll|}
\hline Complication & Number & $\%$ \\
\hline White discharge & 5 & 5.49 \\
\hline Bleeding & 1 & 1.09 \\
\hline Missing strings & 5 & 5.49 \\
\hline Pain abdomen & 3 & 3.29 \\
\hline Expulsion & 1 & 1.09 \\
\hline Perforation & 0 & 0 \\
\hline
\end{tabular}

\section{Infection}

Infection was reported in 5 women for $5.49 \%$ of study population. Patient were adequately counselled and treated conservatively with clingen vaginal pessaries and reassured later discharge subsided. IUCD was not removed and was medically managed.

\section{Bleeding}

Excessive Bleeding was reported in 1 women accounting for $1.09 \%$ of study population. The patient went nearby peripheral health centre and got apprehended and got PPIUCD removed at periphery health centre.

\section{Missing strings}

Missing strings was reported in total 5 women (5.49\%) of which 3 women had intra-caesarean insertion and 2 had insertions following vaginal delivery. Majority of missing strings were reported in women who had intra caesarean insertions $(5.49 \%)$ than insertions following vaginal delivery $(2.19 \%)$. In these women presence of PPIUCD at fundus of uterus was confirmed by ultrasound scanning.

Table 12: Missing strings.

\begin{tabular}{|lll|}
\hline Missing strings & Number & $\%$ \\
\hline caesarean insertion & 03 & 3.29 \\
\hline vaginal delivery & 02 & 2.18 \\
\hline
\end{tabular}

Out of 100 women, 3 women (3.29\%) had got IUCD removed. out of 3 women, 1 woman $(1.09 \%)$ got IUCD removed because of excessive bleeding (1.09\%), 1 woman $(1.09 \%)$ got it removed because of social factors displaying attitude regarding misconceptions about IUCD.

Table 13: Cause for removal.

\begin{tabular}{|l|l|l|}
\hline Cause of removal & Number & $\%$ \\
\hline Excessive bleeding & 01 & 1.09 \\
\hline Social factor & 01 & 1.09 \\
\hline Planning pregnancy & 01 & 1.09 \\
\hline
\end{tabular}

About 1 woman $(1.09 \%)$ got removed because planning pregnancy. When period of removal was considered, 1 women $(33.3 \%)$ had got it removed within first 1 month 
following insertion, other woman $(33.3 \%)$ in between 1-6 months and last women (33.3\%) after 6 months.

\section{DISCUSSION}

In this study, the proportion of parturients accepting PPIUCD and their socio-demographic and obstetric characteristics was determined. Majority of the women $(72.01 \%)$ in the study population had at least a primary level of education. Acceptance of the use of PPIUCD was higher among women with secondary education $(23.4 \%)$, than those with no formal education $(13.4 \%)$. This could be reasoned out that educated women have high acceptance than the less educated women. This was similar to a study done in Egypt by Safwat et al where women with no formal education had an acceptance of $9.4 \%$. while those with formal education was $19.4 \% .^{3}$ Education has a positive effect on modern contraceptive use as shown in a study done in Zimbabwe. ${ }^{4}$ It was only apparent among women who completed secondary education (12 years or more). Women with secondary education has increased acceptance rates similar to study done by Sharma A et al. ${ }^{5}$

According to Thomas et al, the World Bank Economic Review, women who are educated were about twice likely to use modern contraceptive methods as compared to women who did not complete primary level of education. ${ }^{6}$

Although studies show that acceptance of PPIUCD was higher in multiparous women then in primiparous women but in Indian scenario contraceptive prevalence shows predominance of non-reversible methods, particularly female sterilization, limited use of male/couple dependent methods and high discontinuation rates..$^{3,7}$

In present study, primiparous women accounted for major proportion of acceptors of PPIUCD i.e. $92 \%$ and $8 \%$ were multiparous. Among the multiparous women, most of them preferred permanent sterilization procedure over PPIUCD.

Most of women and health care workers in our community were not aware of the PPIUCD. In present study most, women were counseled regarding PPIUCD during antenatal period, early labour or postnatal period because it was only opportunity to provide women with information about PPIUCD. Our hospital being a referral centre and maximum number of women delivered in our hospital are being referred from periphery who visit hospital for first time at the time at the onset of labour pains.

PPIUCD is relatively new method of contraception in this community. Counseling along with partner was more effective8. Now government has been taking efforts to train health care workers in periphery and provide them knowledge of PPIUCD. Efforts are made to create awareness about PPIUCD among pregnant women during their antenatal visit by appointing PPIUCD counselors in our hospital.

In present study we have inserted PPIUCD within 10 minutes of delivery of placenta $(42 \%)$ and during scheduled caesarean section $(58 \%)$ rather than in immediate post-partum period of 48 hours, because they may be experiencing perineal pain and other social factors may play a role which make women to opt out from accepting PPIUCD.

Major portion of women $(58 \%)$ in present study had visited to hospital personally for follow up and minor portion $(33 \%)$ who could not come for hospital visits were followed up on telephone. These minor portions of women expressed inability to travel for many reasons like staying in neighboring states, financial cost for travelling, no family member to accompany them with baby, etc. For similar reason most women $(83 \%)$ could not review on exact 6 weeks follow up dates, though they followed up sometime after 6 weeks. A small proportion of women (16.4\%) reviewed with 6 weeks for follow up for reasons like bleeding, pain abdomen, white discharge and in fear of long strings felt personally near perineum. The follow up rates were similar to that of Ranjana et al study. ${ }^{8}$

There were no serious complications in present study. Expulsion rates of PPIUCD in present study was $1.09 \%$. Expulsion $(1.09 \%)$ was seen within one month. Studies done in many countries like Belgium (4\%), Chile (7\%) and Philippines (19\%) showed expulsion rates ranging from 4 to $16 \%$ at one month follow up. Cheng et al in his study showed low expulsion rates can be achieved by post placental insertion and high fundal placement of IUCD.In Ranjana et al study expulsion rates were $5.07 \% .^{9,10,11}$

In present study expulsion rates were low compared to other studies may be attributed to skill and training of the person inserting IUCD and also use of Kelly's placental forceps which is $32 \mathrm{cms}$ long which ensures high fundal placement of IUCD and insertion of PPIUCD by an adequately trained provider. There was no misplaced IUCD in present study. In one study done by Sofat et al in India 4.3 per cent of cases had IUD slid in cervical canal. ${ }^{12} \mathrm{O}$ 'Hanley Huber et al in his study has suggested that timing of insertion, type of IUD, insertion technique and experience of provider play significant role in reducing complete and partial expulsion rates. ${ }^{13}$

No evidence of upper genital tract infection in present study. Only white discharge was seen in 5 patients $(5.49 \%)$ at follow up. The results were similar to the study done by Satyavathiet al in which there was no PID. ${ }^{14}$ The results were similar to study done in Kenya and Mali which indicated rate less than $2 \% .^{15}$

A study conducted in 13 countries studied infection (PID) due to IUD. They have reported similar rate of infection with immediate insertion and interval insertion. ${ }^{16}$ 
In another study done at Peru infection rates was found to be $0.1 \% .{ }^{17}$ Cole et al. reported gross life table PID rates at one month of 1.1 per 100 women. ${ }^{18}$ O'Hanley Huber et al suggested that infection rates varied in different studies and the infection rates were found to be similar to those reported with interval IUD insertions. ${ }^{13}$ There is general agreement that postpartum insertion does not increase the risk of infection.

Bleeding was reported in about $1.09 \%$ of women in present study. Phatak and Chandrokar reported abnormal bleeding in $15.6 \%$ of post-partum insertions. ${ }^{19}$

In ManjuShukla et al study high rates of menorrhagia due to IUCD of about $27.2 \%$ and most responded to medical management IUCD was reported to be removed in only 65 patients out of 283.There was no significant difference found in incidence of excessive bleeding. ${ }^{20}$

In present study missing strings were reported in $5.49 \%$ of women. Ultrasound confirmed IUCD in situ. Majority of strings were found missing in women (3.29\%) who had intra caesarean insertions this indicates possible reason could be retraction or curling of strings into the uterine cavity or in endocervical canal.

In an Indian study done by Manju Shukla et al showed slightly higher rates of missing string rates of $11.2 \% .^{20} \mathrm{In}$ study done at Peru missing string rate was found to be $7.6 \% .{ }^{16}$

No case of uterine perforation was reported. About $83.51 \%$ of women continued with PPIUCD without any complaints. There was no failure rate reported in women who are continuing it for more than a year.

Present study showed discontinuation rate of about 3.29 $\%$ for some or other reasons. Removal rate was maximum in first 6 months of insertions. Bleeding, social factor and patient wants to plan pregnancy were reasons for removal.

Most women and their family had misconceptions regarding IUCD. Many women expressed fears that IUCD could ascent into their chest or lost in abdomen and it could lead to loss of weight causing weakness and chronic illness. Other concerns commonly expressed was that once inserted they can't conceive for a period of 10 years till its effectiveness wears off, they lacked the knowledge that it can be removed as and when she desires pregnancy. Many women felt the need to discuss with partner and mother in law. In few cases women got it removed as husband and family members refused. In present study majority of women had feared of pain and heavy bleeding. At our institute only $2.18 \%$ ( 2 women) of women with IUCD was removed for any reason.

Absence of uterine perforation, extremely low rates of expulsions $(1.09 \%)$, infection $(5.49 \%)$ and no reported failure rates are strong indicators of safety.

\section{CONCLUSION}

The acceptance of PPIUCD is high in parturients as they are more receptive to contraceptive methods. Counseling has significant impact; preferably couple should be counseled together. PPIUCD was demonstrably safe, having no reported case of uterine perforation. Expulsion rates are low implying more retention rates, thus more effective. No failure reported in women using PPIUCD for more than a year. Fewer incidences of complications like infection and bleeding. Intra caesarean PPIUCD insertion could be prudent in cases where obstetricians are in dilemma to do concurrent tubectomy.

To improve acceptance and to remove misconceptions regarding PPIUCD community should be educated. Myths and fear associated with IUCD usage and public awareness regarding the concept of PPIUCD can be improved by mass media approach. Special training programmes should be held by the government to train many doctors and health care workers how to insert PPIUCD thereby achieving proper placement of IUCD and reducing the rates of expulsion and other complications.

\section{ACKNOWLEDGMENTS}

Authors would like to thank Department of Obstetrics and Gynecology, Bangalore Medical College, for their cooperation extended throughout this study.

Funding: No funding sources

Conflict of interest: None declared

Ethical approval: The study was approved by the Institutional Ethics Committee

\section{REFERENCES}

1. Marston C. Report of a WHO Technical Consultation on Birth Spacing Geneva Switzerland 13-15 June 2005.

2. PPIUCD Reference Manual, Ministry Of Health and Family Welfare, Feb 2011,10,24. Available at http://www.nrhmtn.gov.in/modules/PPIUCD\%20Ref erence\%20Manual.pdf.

3. Safwat A, Mohamed Momen A, Kamel Omar M, Shaaban HT, Salem. Acceptability for the Use of Postpartum Intrauterine Contraceptive Devices: Assuit Experience, Medical Principles and Practice 2003; 12(3):170-5.

4. Mishra S. Evaluation of safety, efficacy, and expulsion of post-placental and intra-cesarean insertion of intrauterine contraceptive devices (PPIUCD). J Obstet Gynecol India. 2014;64(5):33743.

5. Sharma A, Gupta V. A study of awareness and factors affecting acceptance of PPIUCD in SouthEast Rajasthan. Int J Community Med Public Health. 2017;4(8):2706-2710. 
6. Thomas D and Maluccio J. Fertility, Contraceptive Choice, and Public Policy in Zimbabwe. World Bank Eco Review. 1996;10(1):189-222

7. World Contraceptive Use 2010, United Nations, Population Division, Department of Economics and Social Affairs.

8. Sanskriti P, Amita T, Pratima M, Rupali D, Jyotsna S, Kumar A. Exploring reasons behind Low acceptance for PPIUCD in postnatal women. New Indian J Surg. 2011;2(4):246.

9. Verma A, Chawla I. A follow up study of postpartum intrauterine device insertion in a tertiary health care centre. Int J Reproduct, Contracep, Obstet Gynecol. 2017;6(7):2800-5.

10. WHO Report. Mechanism of action, safety and efficacy of intrauterine devices. World Health Organ Tech Rep Ser 1987;753:1.

11. Chi IC, Wilkens L, Rogers S. Expulsions in immediate postpartum insertions of Lippes Loop D and Copper $\mathrm{T}$ IUDs and their counterpart Delta devices - an epidemiological analysis. Contraception. 1985;32(2):119-34.

12. Sofat R. Postpartum CuT insertion - a trial. 4. Indian J Maternal Child Health. 1990;1(1): 23-42.

13. O'Hanley K, Huber DH. Postpartum IUDS: keys for success. Contracep. 1992;45(4):351-61.

14. Maluchuru S, Aruna V, Prabhavathi N. Post-partumintrauterine device insertion-2yr experience at a tertiary care center in Guntur medical college/govt. general hospital, Guntur. IOSR J Dent Med Sci. 2015;14(7):2279-861.
15. Nathalie Kappa et al Intrauterine device insertion during the postpartum period:a systematic review Contraception.2009;80(4);327-36

16. Lopez, Grimes, Szpir (Family health international/CRTU 7. programme). Immediate postpartum insertion of an IUD is safe and effective. Global health technical briefs. 2007. USA: USAID (United States Agency for International Development and Family Health International); 2007.

17. Cole LP, Edelman DA, Potts DM, Wheler RG, Laufe LE, Postpartum insertion of modified intrauterine devices, J Reproduct Med. 1984;29(9):677-82.

18. Phatak L, Chandorkar KA. An experience with immediate postpartum and postabortalIUD insertions. B. Disappearance of IUD threads. In: Zatuchni GI, ed. Postpartum Family Planning. New York: McGraw Hill, 1970,299-306.

19. Shukla M, Sabuhi Qureshi C. Post-placental intrauterine device insertion-A five-year experience at a tertiary care centre in north India. Indian $\mathrm{J}$ Med Res. 2012 Sep;136(3):432.

Cite this article as: Tirupati L, Shivaraju $\mathrm{P}$, Lingegowda K, Srinivasan S. Enhancing contraceptive usage by immediate postpartum intra uterine contraceptive device insertion with evaluation of safety, acceptability and expulsion. Int J Reprod Contracept Obstet Gynecol 2018;7:4120-6. 